\title{
Conversations About Responsible Nanoresearch
}

\author{
Kamilla Lein Kjølberg • Roger Strand
}

Received: 9 November 2010 / Accepted: 28 February 2011 /Published online: 3 April 2011

(C) The Author(s) 2011. This article is published with open access at Springerlink.com

\begin{abstract}
There is currently a strong focus on responsible research in relation to the development of nanoscience and nanotechnology. This study presents a series of conversations with nanoresearchers, with the 'European Commission recommendation on a code of conduct for responsible nanosciences and nanotechnologies research' (EC-CoC) as its point of departure. Six types of reactions to the document are developed, illustrating the diversity existing within the scientific community in responses towards this kind of new approaches to governance. Three broad notions of responsible nanoresearch are presented. The article concludes by arguing that while the suggestion put forward in the EC-CoC brings the concept of responsible nanoresearch a long way, one crucial element is to be wanted, namely responsible nanoresearch as increased awareness of moral choices.
\end{abstract}

Keywords Responsibility - Governance · Europe · Codes of conduct

The research that is reported in this paper has been developed and conducted together with our colleague, Fern Wickson. We also especially want to thank the participants at 'Walkshop' in Aurlandsdalen September 2009 for inspiring discussions and feedback.

K. L. Kjølberg $(\bowtie) \cdot$ R. Strand

Centre for the Study of the Sciences and the Humanities, University of Bergen,

P.O. Box 7805, 5020 Bergen, Norway

e-mail: kamilla.kjolberg@svt.uib.no

\section{Introduction}

Nanotechnology and the Attention to Governance in Europe

This paper starts from an interest in responsible research, and the recent focus on this in relation to the development of nanoscience and nanotechnology (nanoST). We are particularly interested in what responsibility really means in the context of an emerging technology like nanoST. The introduction takes a closer look at the notion of responsibility and we seek to understand better how it has come to be so central in debating the governance of nanotechnology. The remaining parts of the paper focus on findings from empirical work exploring the notion of responsible nanoresearch in the context of governance. These findings are then discussed against the concepts of responsibility found in the theoretical and philosophical work of Luigi Pellizzioni and Hannah Arendt.

Early and continuous funding to research into ethical, legal and social aspects (with the acronym 'ELSA', or short form '-ethics') has accompanied the development of nanoST with the theme of governance as one of the important topics from the beginning [12]. This paper will focus on Europe, as by the time the research for this paper took place (in 2008 and 2009), it was mainly here one could find attempts at institutionalisation of 'governance of (nano)science'. A useful perspective on governance of science within the European Union is that of the larger political 
challenges of constructing a common European identity [14] and European citizenship [19]. In its White Paper from 2001 [5], the European Commission proposed 'European Governance' as the solution to the paradox of the simultaneous public distrust in the EU level institutions and the public demand for global challenges to be approached above the national level. Tallacchini [19] points to how "new forms of normativity" (p.282), such as soft law have become increasingly common in EU as a result of "regulatory needs in the so-called knowledge society" (p. 282), but that "its statute is unclear" (p.282). With this, "nanotechnology has become a test case for a new sort of governance. It is an opportunity to reimagine the relationship between science and democracy.". ${ }^{\prime}$

A timely question is whether governance should facilitate smooth technological development, or provide a way in which to put other values above that of economic growth and progress? Or broader: is governance still a good idea if it slows down innovation? These kinds of questions have led to several attempts to rethink the notion of responsibility in relation to nanoST. This again, may be seen as a willingness to look for alternatives to the standard risk-benefit management regime and institutions and practices inspired by neoclassical economic theory. As stated about governance in the final report of the EC funded project Risk Bridge, "[...] there are inherent tensions between those three functions of stimulating-controlling-facilitating debate. Promoting innovation aims at realizing potential benefits, but, as a driver for change, it is, in the same time, a 'creator' of uncertainty, and thus renders more and more difficult the tasks of 'controlling'." ([3], p 121). This tension exists in public participation, which has been widely discussed in fora such as the present journal, but becomes perhaps even more crucial in another main strand of governance: the integration of social scientists in natural science research practises and communities, and the encouragement of consideration for the societal aspects of research within science itself. This has been looked into far less, and is what will be the attention of the remainder of the present paper.

Looking at policy and funding of research in EC, a site of particular interest is the Unit L3 of Governance

\footnotetext{
${ }^{1}$ http://www.demos.co.uk/publications/nanodialogues, (last accessed March 2010)
}

and Ethics at the Directorate L-Science, Economy and Society (under Directorate-General for Research) (hereafter Unit L3). Through the program for 'Science in Society' a number of research projects on the governance and ethics of nanoST have been initiated. The academic interest within ELSA research for governance of science and technology, as well as the need for the Commission to show that it looks at governance [5], have been satisfied in relation to nanoST, through an instrument for research interests to be installed cross-thematically ${ }^{2}$ between different lines of research (here 'nanoST' and 'the testing of approaches for governance'). Another major initiative of the Unit L3 is the code of conduct for responsible nanoresearch [6], which is the starting point for the empirical part of this paper.

European Research and the Code of Conduct for Responsible Nanoresearch

The publication in 2008 of a EC code of conduct for nanoresearch [6], is one of the few concrete actions into research by an authority that may be seen to be in line with the academic discourse on broad and inclusive governance and the 'responsible development of nanoST'. The document is entitled 'European Commission recommendation on a code of conduct for responsible nanosciences and nanotechnologies research" (EC-CoC). Interestingly, it does not provide a definition of responsibility (as we shall see later; this is quite common). Instead, it presents seven principles, first briefly described and then used as the foundation of a number of guidelines for action. The seven principles are: Meaning, sustainability, precaution, inclusiveness, excellence, innovation and accountability. 'Sustainability', for instance, is described as "N\&N research activities should be safe, ethical and contribute to sustainable development serving the sustainability objectives of the Community as well as contributing to the United Nations' Millennium Development Goals. They should not harm or create a biological, physical or moral threat to people, animals, plants or the environment, at present or in the future." While 'innovation' is described as: "Governance of $N \& N$ research activities should encourage maximum creativity, flexibility and planning ability for innovation and growth." What appears to be implicitly

\footnotetext{
${ }^{2}$ Personal communication René von Schomberg, March 2009.
} 
communicated is that adherence to these seven principles indeed defines responsible nanoresearch. Clues to what notion of responsibility the EC-CoC builds on, and what kind of problem it seeks to solve is perhaps to be found in another EC document, a working document from 2007 [20]. Here, René von

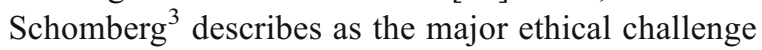
of today that "[s]cientists and engineers may even claim that the possible applications and/or use are not part of their role responsibility as scientists or engineers." (p. 10-11), or more generally, that there exists "...an imbalance in the relation between the individual's responsibility for a particular and temporal role and the collective responsibility which is represented by the simultaneous fulfilment of great number of roles for the long-term." (p. 10). As a solution "an ethics of collective co-responsibility" (p. 11) is proposed. Public debate, transdisciplinary deliberative technology assessment and foresight activities, as well as the constitutional change needed to implement these kinds of approaches are described as part of the solution, as "the absence of adequately deliberative forums is certainly one reason why we are not yet able to democratically plan our technological development. (p. 13)". The precautionary principle is presented as an example of how "[t]he very implementation of such a principle requires new and badly needed intermediate deliberative science-policy structures (p. 13)". The working document concludes by using the example of nanotechnology to illustrate how deliberative procedures between the different political levels can be the approach to answer the "crucial question [...of] who will decide, under which procedures, on what issue and within what timeframe" (p.21). Especially interesting in the context of this paper is the role that the scientific community is envisioned in this example, which is to "work with provisional voluntary guidelines for research and applications, to allow for flexible adaption to new developments. It is probably too early for particular measures, yet, deliberation on the quality and availability of scientific information should be held on ongoing basis to enable to monitor scientific and technological development." (p.23).

\footnotetext{
${ }^{3}$ Von Schomberg is at the EC, DG Research, Unit L3 of 'Governance and Ethics' at the Directorate L, and has as such had an active role in the development of the EC-CoC.
}

In the 'responsible development of nanoresearch', what is it that researchers and nanoST stakeholders are responsible towards? According to Tallacchini [19], "[t]hough all these new experimental practices sound promising, the regulatory reality of emerging technologies appears quite traditional." (p.302), "[t]he idea of science endorsed by the EU has not gone too far from the traditional image of the scientific community (Polanyi 1962; Merton 1968)." (p. 291). For many, independent of the task one performs as researcher, being a responsible scientist is to develop new knowledge, be it basic, applied, industrial or, as commonly seen for nanoST, something in between these categories. In Polanyi's [18] classic treatise on the subject, responsible science essentially is a commitment and love for truth: "Yet, from time to time certain visions of the truth, having made their appearance, continue to gain strength both by further reflection and additional evidence. These are the claims which may be accepted as final by the investigator and for which he may assume public responsibility by communicating them in print." (p. 30). And it can only take place if given freedom from direction from politics: "The government of science [...] exercises no specific direction on the activities under its control." (p. 49). Commenting on the EC-CoC in the journal of Nature Nanotechnology, Richard Jones ([11]; see also [4]) writes that still "[m]any scientists believe in a division of moral labour-they do the basic research that, in the absence of direct application, remains free of moral implications; technologists and industrialists then take responsibility for the consequences of applying that science, whether those are positive or negative."

Any new characterisation of researcher's responsibility challenges many established norms and ideals for scientific practice to which scientific practitioners are introduced through their education and training. At the centre of these clashing visions about responsible nanoresearch are the nanoresearchers. They find themselves between traditional ideals of science and new - and in part vaguely articulated and competing-demands on the role as researchers. Governance distributes responsibility across the traditional walls between science, politics and citizens. Allowing once again the widely used metaphor of river streams, responsibilities for unanticipated effects 'downstream' of research are 
now also distributed upstream (with the citizens of the whole society) and midstream (with the scientists).

As such, the EC-CoC as a guideline for responsible research does not enter into a vacuum, but into a rather crowded space. The EC-CoC document is placed in the midst of these tensions when over the first 3 pages it is positioned among other EU communications, action plans and activities. On the one hand it links itself to the 2004 Communication "Towards a European strategy for nanotechnology" and the 2005 "Nanotechnology Action Plan", which identifies "actions aimed at creating the Community added value necessary to remain competitive in this sector while ensuring its responsible development" ([6], p. 2). On the other hand it is placed in the tradition of the strategy on sustainable development ${ }^{6}$ "centred on objectives of environment and health protection and poverty eradication." ([6], p. 3).

On this background, the research and discussion in this paper will be pursued along two broad lines: First, the interest in how the nanoresearchers themselves respond to the EC-CoC and what sort of reflections that are triggered when governance enters the sphere of professional responsibility and identity. Secondly, a broader view is taken on how the reflections from the nanoresearchers can be seen to support three different answers to the question of what responsible nanoresearch might be. The tensions described above, between different visions for governance, inform both of these lines of interest.

\section{Method}

The empirical research underlying this paper was performed as part of a project where we have been working as ELSA researcher associated with the nanoscience initiative at the University of Bergen (Norway). ${ }^{7}$ All the conversations with nanoresearchers to be presented were conducted together with our colleague, Fern Wickson, who also took part in subsequent stages of discussion and analysis.

\footnotetext{
$\overline{{ }^{4} \operatorname{COM}(2004)} 338,12.5 .2004$

${ }^{5} \mathrm{COM}(2005)$ 243, 7.6.2005

${ }^{6} \mathrm{http} / /$ ec.europa.eu/environment/eussd/, (last accessed March 2010)

${ }^{7}$ The research was funded by the University of Bergen and the Nanomat program of the Norwegian Research Council.
}

As follows from the above presentation of motivation and theoretical perspective, in this study we have wanted to take the inherent tensions in how the notion of 'responsible nanoresearch' is in use in the EC as a starting point for further reflections about what responsible nanoresearch might mean. The EC-CoC provided the apparently perfect case-study to develop our own thinking around 'responsible nanoresearch' by understanding better how the $\mathrm{EC}-\mathrm{CoC}$ is perceived by nanoresearchers, and to test out our own theoretical position with them. At the same time we wanted to understand better what responsible nanoresearch looks like from the point of view of those working with the governance of science in the Europe Commission. As ELSA-researchers, we often find ourselves providing connections between the "world" of governance of science and that of science itself. Hence, we have not been interested only in the individual nanoresearchers, but also in the research institutions and in tracing responsibility between these two arenas in which it is played out. The aim has been to challenge own ideas of responsible nanoresearch from both these directions, as well as searching for clues to how responsible nanoresearch might be achieved.

The main part of the approach has consisted in leading a series of conversations with nano-researchers at our university in Bergen, about the EC-CoC. These conversations form the core of the research. Secondly, this was complimented by conversations with three representatives from the EC; one nanoresearcher, one employee of the Unit L3 and one social scientist working with science policy. Talking with individuals who hold positions in the $\mathrm{EC}$, with different kinds of relationships to the EC-CoC, contributed to deepen the understanding of the $\mathrm{EC}-\mathrm{CoC}$ and of the notion of responsible nanoresearch from various points of view within the European Commission. While observations from the conversations with nanoresearchers in Bergen, making up the core of the research for this paper, will be presented under "Exploring the Nanoresearcher Role" below, the conversations with representatives from the EC mainly serve the purpose of adding that different perspective in the succeeding discussion.

The series of conversations with nanoresearchers were designed so as to cover the plurality existing among the nanoresearchers at our own university. At the time of the study, we had been working as associated ELSA-researchers in the nanoresearch community at the university for about $2-3$ years. We 
therefore knew these researchers well from a number of collaborations, teaching activities, seminars and formal and informal meetings over the years, in relationships characterized by mutual trust and respect. When we approached them to ask if they would be willing to meet us for a formal conversation about the EC-CoC, they all agreed to make an appointment, and to prepare by reading the $\mathrm{EC}-\mathrm{CoC}$ document. Depending on the mode of our previous contact with the researchers, we approached them either as individuals or as groups. In line with the aim to elicit the plurality of positions and perspectives within the research community, it was an advantage to talk to scientists in different settings, and to talk to researchers in various stages of their scientific career. In the following analysis we do not seek to explore whether these different settings provided different kinds of responses, but see them as contributing to provide diversity. We spoke individually with three senior researchers, attended a research-group (mix of senior and junior researchers, ten in total) in their regular weekly lab-meeting and met after work hours with a group of 4 Phd-students. In terms of disciplines, the researchers represent the fields of physics, chemistry and molecular biology, all involved, however, in the interdisciplinary nanoscience research platform. All of the 17 researchers define themselves as working in basic research or risk-research. Each of the conversations lasted for about an hour, and we took extensive notes, and in one instance the conversation was also recorded. During the meeting, the researchers were left relatively free to steer the conversations as they wanted. However, a hard copy of the EC-CoC document was always there, and we tried to tie the conversation directly to the document and concretely to the text and formulations within it whenever possible and reasonable.

The conversations where conducted over a period of 9 months, from August 2008 to April 2009, and the fact that they were spread out in time allowed us to alternate between exploratory proximity and reflective distance during the time of the study. We also, in manner of conducting our ordinary tasks at the university, met and collaborated with the conversational partners in other settings over the months that the study took place. This dialectic approach, where we varied between exploratory conversations on the one hand, and individual reflection and discussion in our research group on the other hand, proved fruitful. One concrete effect of this open method approach was that, early on in the research, it became evident to us that it was our investigation that drew the attention of the researchers to the EC-CoC for the first time. Accordingly, we decided that our role as ELSA researchers had to be thematised within the frames of the study. Indeed, it led to reflections on the implications of the proliferation of this kind of researchers for nanoST in general part of the object of investigation.

\section{Findings from the Conversations}

\section{Exploring the Nanoresearcher Role}

This section of the paper presents observations from conversations with 17 nanoresearchers. Based upon these conversations we suggest six "types" of researchers, or perhaps ways that researchers present themselves in discussion. The "types" are created through simplifications and idealisations of their responses to the EC-CoC, and lines of arguments related to the understanding of the role as researcher and of researchers' responsibility. All the viewpoints and positions presented below have their grounding in the conversations, and all the main arguments we came across are represented. Not any of the types corresponds to one individual researcher in our material, and not all of the types exclude each other. Furthermore, especially in the conversations we had with groups of researchers, different lines of arguments shifted in dominating the conversation. The reasons for presenting the material as types are twofold. First, the wish to de-identify the conversational partners and second, the way it allows showcasing the plurality of perspectives without the full complexity of reality.

A first observation, however, was unanimous and so straightforward that it just requires a plain sentence: All the researchers described themselves as responsible, and shared the view that researchers in general are responsible. As the rest of this section will show, however, we observed quite different views about what this means in terms of what scientists are responsible for, and who they are responsible towards.

\section{The Excellent Nanoresearcher}

"Excellent nanoresearchers" are characterised by a self-image of scientific excellence and are very aware that they and other senior scientists have worked hard 
to get where they are and that it takes decades to develop the skills required to understand science at the level they do. For them, this qualifies them to be trusted by the members of society to do their best to work in their best interest. It remains obvious to them that scientists are the ones most qualified to make decisions about priorities within research, and that one cannot and should not attempt to steer science towards short term goal. "Scientists are not treated as they should by the politicians. They do not understand what it is all about." ${ }^{8}$. They strongly believe that the skilled hard work and creative powers of scientists are society's best bet at getting out of challenges and threats. Given resources and freedom, science will most likely bring benefits, but since it ultimately is about exploring the unknown there can be given no guarantees. "Most science is for the waste-bin, [...] but the few percentages that turns out to be important and useful is what brings progress and saves us all". In the mind of an excellent nanoresearcher the EC$\mathrm{CoC}$ threatens the very nature of basic research by aiming to steer it towards objectives defined within the short term frame of today's political agenda. "This document does not allow for science for the sake for science, which we need in order for long term breakthroughs". Sustainability is among these short term goals for them, with the idea that if all basic research has to show that it will contribute to sustainability, this inhibits and restrains the freedom and creativity vital to development. Since "[a]s humans we all want the same; a clean environment and good health", it is frustrating when innovative research that may bring far-reaching progress in these areas is slowed down by tedious political debate and short-sightedness. An excellent nanoresearcher is however also opposed to hard regulation of research, and would not hesitate to come around this by for instance inventing goals for projects in funding applications to obtain financial support for what is seen as important and interesting research. "I think it may be useful to know [the structure of $\mathrm{xxx}$ ], but not why. For the funding bodies, I can think of reasons for how this knowledge may be used, but the reason I do it is because I find it appealing to find out". The excellent nanoresearchers' response to the EC-CoC is to prioritise the principle of freedom and to place that

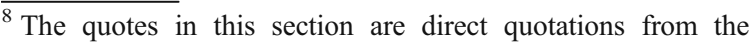
conversations.
}

above all the principles in the code. In this way they circumvents the changes that the documents seems to be aiming to enforce, and remain true to the traditional ideals of science that they believe in and under which they have succeeded in achieving their positions.

\section{The Subordinate Nanoresearcher}

"Subordinate nanoresearchers" express an understanding of their own role as researcher as that of performing the tasks entrusted to them by their superiors in the research group and in the laboratory. They do not express particular interest in issues related to the social context of their work. "I have never seen this [the EC-CoC] before. Should I have been introduced to it? By whom?". When presented with the EC-CoC, they are in doubt about how to respond because they see it as concerning issues that are outside the scope of their role. They do not wish to go along with the demand to reflect upon these matters in conversation, pointing out that these kinds of considerations belong elsewhere in the hierarchy. "I do not know how it applies. The project is given to me by my supervisor." When subordinate nanoresearchers still agree to talk to us, it is mainly to express these kinds of hesitations, and to suggest that we speak to a senior colleague.

\section{The Social-Democrat Nanoresearcher}

Social-democrat nanoresearchers are interested in, and articulated about, science policy and their own role as researchers. Nevertheless, they struggle to properly grasp what kind of a document the $\mathrm{EC}-\mathrm{CoC}$ is. "The objective with the document, as I see it, is partly to pave the way for an ethics, maybe, for what is here called stakeholders in nanoresearch, and to make that clear both through these principles but also to communicate to the public the restrictions that science put upon itself." They fully support the sections encouraging more communication from science to the broader community ("If you believe in this thing with democracy-you have to let go a bit. You have to allow for the public to have a say."), because they think it is important that the public get better educated in matters of natural science in order to be involved in deliberative democratic processes for science and technological. "To some extent 
communication would help, it could fix a lot if more people understood the science involved." To them, many of the listed principles at first seem obvious and vague, but in practical terms some of them seem to be in conflict with each other. "What you have here is in a way different sets of values, the generic with long duration, and they are ok, but, in addition you have those with a lot shorter duration, and these should have been better grounded." In this way, they point out "[the document] consists of a number of detached guidelines that are put together, but do not relate to one another." One example is the principles of sustainability and innovation. These two principles, as defined by the EC-CoC (see the Introduction to this paper), put competing demands on the nanoresearchers, who on the one hand should contribute to innovations that can fuel the European economy, while on the other hand make sure that their activities do not harm people or the environment. The social democrat nanoresearchers point out that it is not impossible to contribute to growth without harming people, but that it is impossible to guarantee that your contributions to innovation will not create threats at present or in the future. They see the lack of prioritisation between principles as problematic, and as researchers they are clear about what must be their main responsibility: "For me, it is obvious that good laboratory practise and security for my employees must have the highest priority", except from that, "If you have taken all reasonable measures at the time, then that must be what can be required from the researcher." It is the responsibility of the regulatory authorities to take an overall perspective and carve out the main direction of the whole scientific enterprise.

\section{The Risk-Minded Nanoresearcher}

Risk-minded nanoresearchers have a deep commitment to what they see as a task of controlling that the materials used in science and industry are safe. They see this as an important job that someone has to do. "We investigate the material $[\mathrm{xxxx}]$. No one else is investigating this, because it is said to be safe. They were saying that we should look at something else, because we would not get any interesting results, and never get anything published." It is crucial to their identity and motivation that it is possible, given enough time and resources, to control the risks stemming from science. They welcome the EC-CoC as recognition from the authorities in Europe of the important work they are doing. "I am happy with this document; it says that funding should go to projects as far as the risk is also evaluated." Still, they express frustration about the lack of concrete measures and formulations onto which to build action. They also express that the document seems to be designed with good intentions, but with little force behind it. If it had been important, they believe, it would have come with sanctions for not meeting the terms. They will still refer to it when arguing for more funding and more attention to risk-research, which they believe is what is needed to satisfy the principles in the code.

\section{The Uncertainty-Minded Nanoresearcher}

Uncertainty-minded nanoresearchers work with riskresearch, but the overwhelming ignorance about nanomaterials has led them to doubt that more toxicology research alone can rule out entirely the possibility of negative consequences. The vast need for research about the behaviour of nanomaterials makes them experience their job as extremely important, but the suspicion that one can never obtain certainty interferes with their motivation. "The results vary so much! But because of lack of reference materials and proper methods, it is hard to say what are real results and what are the result of the method we use. [...] The problem now is that the methods for testing are not reliable for nano. The more we added, the less toxic $[\mathrm{xxxx}]$ got!" They welcome what they see as recognition of the need for the kind of research they are involved in from the EC in the code. But the EC-CoC also resonates with their doubts, by encouraging them to think about what it means to be a responsible nanoresearcher. "You are accountable as long as you do your research, follow the ethical rules, do the best you can and are open about what you do, I think..."

\section{The Ironic Nanoresearcher}

Ironic nanoresearchers, as most of today's senior nanoresearchers, were originally trained within one of the standard disciplines of physics, chemistry or molecular biology. The re-interpretation of their research-groups, research-activities and of themself as 'nano' (while the work they do by far remains the same) have been for administrative and political reasons more than scientific ones. NanoST is priori- 
tised by the university, it attracts funding and it creates attention to important research that has been neglected far too long. They believe that crossing the disciplines, there are strands of research that has the potential that has come to be associated with nanoST, but what they do is far from fulfilling these kinds of expectations. "If you go deep, there is something genuinely different about the nano-label [...] they invented a car at nanoscale that could move. It shows that man now have the ability to make and manipulate things at this scale." The ironic nanoresearchers have taken on the nano-label without feeling entirely comfortable with it, between them they joke about how nanoST does not really exist, even if they are nanoresearchers (hence the term 'ironic'). Whenever referring to themselves as 'nanoresearchers', they make sure to also comment upon the political force of this label and the hype that surrounds it. The EC-CoC is a reminder that for some people; many scientists, members of the public and politicians, being a nanoresearcher distinguishes them from other researchers and this creates uncertainty relating to whether the label has unexpected strings attached. "Actually, I have not seen anything in this document so far that is nano-specific. Of course science should 'meet the best standards', but you have a lot of different kinds of research." Now they question whether the bureaucrats in EC expect more in terms of ethical considerations from nanoresearchers, or if they believe that nanoresearchers are less ethically aware or less responsible than other researchers. It becomes of crucial importance to them to clarify the definition of nanoscience, and the relevant criteria for something to qualify as nanoresearch, before even entering into a conversation about the EC-CoC. They need to discuss the premises and justification for the existence of a code of conduct for nanoresearch. It has to be clarified whether there is seen to be something special about 'nano' that warrants particular attention in terms of ethics and responsibility. With an ironic nano-identity, it becomes crucial to clarify that there is nothing in what they do that deserve special ethical attention.

$$
* * *
$$

In the conversations, we observed how the tensions between old and new ideals of responsible research play out in a number of different ways-simplified through the responses described here. What we have wanted to show above is that it is more complicated than to say that 'the old view of responsible research' is in tension with 'the new view of responsible research'. When confronted with a set of principles for responsible nanoresearch, the nanoresearchers we spoke to responded differently. While excellent nanoresearchers for example fundamentally disagree with any blurring of the border between science and politics, social democrat nanoresearchers get frustrated, because to some extent they agree but they do not see anymore how they can act responsibly according to the internally conflicting principles they are presented with.

\section{Exploring the Role of Co-production}

The research for this paper made 17 researchers read the EC-CoC for the first time, several of whom found the document well suited for teaching and said that they intended to use it with their students. That the document in this way is spread through the scientific community and subjected to reflection, criticism and debate is, according to the representative for the Unit L3 that we spoke to, part of the intention. Through the research, we became actors in the governance that we set out to investigate, especially since none of the researchers we approached had read the code and we therefore introduced them to the document.

Several of the conversations started with interactions with 'ironic nanoresearchers', about whether nanoscience exists or not. At the time these exchanges were experienced as quite frustrating for us. The definition of nanoscience was not what we wanted to talk about. We felt as though we had to take a step back and spend large part of the session on what we saw as a distraction from the issue at stake. In reflecting upon this later, we understood that what we assumed to be an acceptable and legitimate premise for the conversations was partly what was at stake for the nano-researchers. For us, the EC-CoC represents an interesting example of an experiment with a new approach to governance applied to the case of nanotechnology. For our conversation partners, however, whether or not the label of nanoresearcher put them in a situation with new expectations and demands was of urgent importance, especially as these demands seemed quite obscure. We also found the practical consequences of the EC-CoC relatively unclear, but while for us this was precisely what was interesting, for the nanoresearchers it was disturbing to discover that the extent to which they did their job 
responsibly might be assessed according to criteria that seemed poorly defined. Independent of possible implications for practise, however, the idea that bureaucrats with, in their mind, limited understanding of science could create a code of conduct for nanoresearch based upon a misunderstanding about the importance and potential attached to this label was experienced as distressing.

The nanoresearchers at our university expressed appreciation for the opportunity to talk to us about responsibility. "I am happy that you introduced me to this [the EC-CoC], I think I should know it. It creates awareness, in a sense. It is only when you meet other researchers that you are able to see your own limitations. It is very good that you approached us with this." The positive response has to be seen in context of the longer term relation we have had with these researchers and previous experiences with discussion of similar issues, which is also part and parcel of the broader push of governance. Even though the researchers' own views on what their responsibility is did not necessarily correspond to the theories and the thinking that has informed the creation of the EC-CoC, our nanoresearch community welcomed the opportunity to discuss these kinds of issues. Many ELSA researchers (the authors of this paper included) see their role as partly to create awareness, reflection and debate in the public and in the scientific community about societal issues related to science and technology. The proliferation of this for nanoST in Europe has succeeded in generating some spaces and opportunities where researchers can relate to the wider social aspects of their research, and at least in our material, the opportunities may have created a further demand. The willingness to enter into these kinds of conversations may therefore be seen as a success for a first step into governance: the empowering of individual researchers by providing training and resources for broader reflection. The EC-CoC goes quite far in describing indirectly the responsible nanoresearcher, but inherent in the description is the mandate to participate in a debate about what it is to be a responsible nanoresearcher. This may lead to a kind of circularity in that it may be said that a responsible nanoresearcher is someone who takes an active part in debating the terms and conditions of responsible nanoresearch. Paradoxically, in our material, some nanoresearchers seem to enter into the conversation precisely to defend the traditional image of the scientific community - and by consequence also the right not to debate the social and political aspects of their research.

The observations from the conversations seem to indicate two obstacles for the EC-CoC. The first is that it is dependent upon distribution (through national states, research councils, university administrations etc.), which in the case of the nanoresearch community at our university seem to have failed. The second is that it seems to have difficulties communicating its intension of being an invitation to communicate back - precisely because it is a publication from EC. We found a fundamental scepticism concerning what it is that the code is trying to do. In all the conversations, the permanency of the code's content was taken for granted by the scientists. Although the discussions often revolved around what was perceived as weaknesses of the document and ideas about how it could have been improved, the researchers never raised the issue that it could be changed. This shows that although welcoming the opportunity to debate this kind of issues, and to some extent feeling empowered to discuss it with us, they did not see themselves in a role as to actively engage, interact or participate in policy_or in fact see EC documents as things that may actually be changed. The deliberative aspect of the code and the fact that it will be revised was highlighted in the conversation with the representative from Unit L3, as well as underlined in the text of the code itself, when it states that "the Member States cooperate with the Commission in order to review this recommendation every 2 years..." (p. 4) and "...this Recommendation also be used as an instrument to encourage dialogue at all governance levels among policy makers, researchers, industry, ethics committees, civil society organisations and society at large..." ( $\mathrm{p} 4)$. The nanoresearchers did not see it as an invitation to participate, but rather as coming from far away bureaucrats with a misunderstood, or at best vague, understanding of science, and with unclear consequences for their practise. "I do not think that it was the scientists that wanted this code. It has come from above. The document is a first step towards legislation. [...] The code doesn't really mean anything. There is a lot of twisting going on." This is an ironic consequence of the lack of communication that this document (from the point of view of the Commission) may be partly a proposition to remedy. One challenge is that it is exactly this involvement that some nanoresearchers resist, because it counters their 
understanding of the role and responsibility they have taken on as scientists.

Summing up, the main observations are: first of all that all the nanoresearchers saw themselves as responsible scientists. Second, that there existed a variety of views on what responsible nanoresearch is (here simplified into six types). Third, that it was we who introduced the nanoresearchers to the code. While they appreciated the opportunity to talk to us about the issues raised in the EC-CoC, it existed confusion about its status and meaning. Forth, that none of the nanoresearchers took the EC-CoC as an invitation to dialogue with the decision-makers. Rather than feeling like partners in a process, they expressed confusion and opposition towards new demands on how to do their job, and some expressed indignation that someone indicated, in their mind, that they were not doing their job responsibly and ethically sound.

\section{Three Broad Notions of Responsible Nanoresearch}

This paper pursues the issue of responsible nanoresearch along two lines. So far, it has focused on an empirical question, namely how nanoresearchers respond to the EC-CoC and what sort of reflections that are triggered when governance enters the sphere of professional responsibility and identity. While maintaining the perspective of the nanoresearcher, in the final part of the paper we shall try to lift the gaze and discuss responsible nanoresearch on a conceptual level, along the line of three broad notions of responsible nanoresearch. The first two notions exist as clearly articulated and contrasting notions in the public and academic debates about science and society of the last few decades. These are also the crystallisation of the main two positions drawn from what was presented above. We shall argue, however, that the conversations also allow for a third notion of responsible nanoresearch, emphasising mindfulness and Hannah Arendt's concept of 'thinking' - providing what we see as an important and perhaps necessary supplement.

In spite of its growing centrality, the notion of responsibility is often left unproblematised and undefined in the policy documents, as pointed out by among others Ferrari and Nordmann [7]. In our view, Pellizzioni [17] provides a useful analytic disentanglement of the notion of responsibility. He suggests that it has taken on different emphasis at different times in environmental policy - and with governance it has shifted again. We find this sorting out of the different meanings of responsibility is valuable, and the analysis is presented here in a very simplified version. Pellizzioni [17] points to four ways that the notion of responsibility is used in the context of environmental policy: Care, liability, accountability and responsiveness. He traces their appearance and emphasis through history. Until around the 1960s, he writes, the idea of responsibility was that of care, driven by 'before the event' motifs and 'in-order-to' factors. The welfare state was responsible in the sense that it knew what its citizens needed and its ability to act accordingly was unquestioned. Increasingly faced with incidents of environmental damage, the emphasis of responsibility (in early environment policies) shifted towards liability, dominated by 'after the event' motifs and 'in-order-to' factors. It became more about legal instrument (such as for example the polluter pays principle) to assign responsibility for events that had already happened, although the notion of responsibility as argued for from within still prevailed. As awareness of growing social complexity, accompanied by decline in legitimacy and authority, increased, the emphasis in responsibility shifted towards the dimension of accountability, dominated by 'after the event' motifs and 'because' factors. This was dominated by the need to justify choices and behaviour in retrospect vis à vis allegation or questions coming from outside/society. Finally, within a theoretical framework of scientific uncertainty the focus of responsibility has tended to shift towards that of responsiveness, dominated by 'before the event' motifs and 'because' factors. Responsibility has to do with answerability to an outside demand to take action in order to avoid situations of damage or harm, " $a$ willingness to understand and confront the other's commitment and concern with our own, to look for a possible terrain of sharing. It entails readiness to rethink our own problem definition, goals, strategies, and identity." ([17], p. 557). Despite the focus here on the willingness to evaluate own goals and identity, it is still a process initiated and motivated from outside. These different ways to understand or put emphasis in the notion of responsibility resonates with the tension described above, which seems to stem from underlying understandings of what it is that one sees oneself as 
ultimately responsible towards: performing the role assigned to the professional in contributing to growth and progress - or towards 'something else', like for example the continuation of human life on earth [10], taking part in the contemplative and active life that constitutes the human condition [1] or being part of the ecological community of beings [13]. We shall now apply Pellizzoni's analysis to the notions of responsibility found (or indeed wanting) in our conversations with the nanoresearchers.

Responsible Nanoresearch as the Traditional Social Contract of Science

According to an excellent nanoresearcher's line of argument, responsible nanoresearch is, in addition to follow formal safety regulations and show good collegial behaviour, to practise within the traditional social contract for science. This is a model that has proved itself to work by giving society progress and benefits based upon scientific knowledge, and hence the most responsible thing to do is to change as little as possible. Above all, academic freedom needs to be protected, so that nanoresearch is allowed to explore unconstrained by political steering. A risk-minded nanoresearcher would agree, but emphasis the importance of complementing all research with robust risk-research. With sufficient money and resources to research into potential adverse effects to health and the environment, one will be able to responsibly control new substances that are commercialised based upon nanoresearch. This line of argument in the scientific community, has support also in the EC (see the Introduction and [3]), in the use of governance as a way to insert more deliberation and openness within the existing institutional framework. The role of the EC-CoC in this respect is that the public can acknowledge that science is concerned with issues such as sustainability and precaution. It should not lead to further institutional changes, but show that the concerns in the public sphere are taken account of also in the scientific community.

Going back to Pellizzioni's [17] four different uses of the notion of responsibility, this resembles accountability, where responsibility is argued for and defined in terms of the ability to justify behaviour. Nanoresearchers main responsibility is to perform research within the political and legal framework provided, and within this framework be able to make account and explain rationally its choices in terms of a risk-benefit argument: the reasonable amount of resources has been allocated to risk-research; the expected benefits exceeded the expected risk and so forth.

\section{Responsible Nanoresearch as Deliberation Across} Levels and Sectors

The view described in the previous section is in tension with views that see responsible nanoresearch as moving in the direction of dissolving the institutional separation between science and policy. This means to go from a traditional Mertonian social contract for science in which science and society are strictly separated domains, to what has been termed a new social contract for science, allowing "society to speak back to science" $[9,15]$. Above, this latter view was presented by social democrat nanoresearchers and it begins from the belief that science and politics, facts and values to some extent are intermingled anyhow. The notion of responsible nanoresearch, then, has a very different starting point. As detailed above, the idea that science and society are intimately entangled often leads to arguments in favour of the democratisation of science, through deliberation and inclusion of citizens and stakeholder in scientific and political decision-making. For the nanoresearcher, this notion of responsibility means to acknowledge the entanglement of science with society and to engage in deliberation about the broader aspects of nanoresearch. It is the profession of nanoresearch that has this responsibility, and the social democrat nanoresearcher would probably agree with the architects of the EC-CoC that what is needed is to get in place functioning institutions where this kind of deliberation and communication is encouraged and facilitated. The EC-CoC is, of course, one attempt to move in this direction. It is telling that the social democrat nanoresearchers, who in principle agreed that they had a responsibility to be engaged in social aspects of their work, articulated deep scepticism towards the decision-making institutions. In being willing to modify their own role, these researchers needed to trust that the other actors involved in the development of nanoresearch would take their responsibilities accordingly. This requires institutions at all levels that are prepared to take the consequences of the insights that are gained from these kinds of deliberations. The fact that different views on gover- 
nance exist side by side in the communications from the EC may create hesitation about making changes in own practise in the nanoresearcher communities, even among those who in principle support many of the changes proposed in governance.

One of the weaknesses of the EC-CoC as a governance instrument seems to be that it does not reach nanoresearchers and other stakeholders in nanoresearch in the intended way. It fails to be perceived as an invitation to dialogue. This may seem banal, but it points to one of the challenges of governance: the EC-CoC attempts to install engagement, and to create democratisation, reflection and deliberation, but being a Commission recommendation it cannot escape the fact that it comes "from above", to the scientists from the authorities. In order for the nanoresearchers to experience agency, there have to be possibilities for them to communicate back into the decision-making system, whether to the university administration, national level authorities or to the European Commission. ${ }^{9}$ The more fundamental challenge is the paradoxical situation that when the authorities instruct through directives citizens and professional groups to get engaged, they may achieve the precisely opposite effect. At least, in order for a document like the EC-CoC to be a platform for communication and deliberation, there need to be in place practices for communication within and across institutional levels. von Schomberg [20] indeed included constitutional change as one of the four needed changes to get to the co-responsibility he proposes. This is, in difference from engagement, one of the things that require political initiative. It is however, far to go to install support and facilitation for deliberation and communication in all levels of science policy and administration. von Schomberg [21] points out that "[t]he EC Code of Conduct also view Member States of the European Union as responsible actors, and invites them to use the Code as an instrument to encourage dialogue [...]" (p. 9). It was pointed out by one of the EC nanoresearcher that certain member states (such as Germany and the UK) in many ways already are more progressive than what is called for by the EC-CoC. The status of the European Union as a collection of individual national states does however provide a challenging institution in which to succeed

\footnotetext{
${ }^{9}$ Norway, where this study was carried out, is not a member of the EU but part of the European Research Area Network.
}

with governance. Conflicting ideas about science policy, within the Commission and within and between nations, makes thorough institutional reform of governance approaches seem rather unlikely in the short term.

Although poorly institutionalised, the practical enactment of deliberation is one of the places where the ELSA kind of researchers is already making a contribution. Ethics courses, interdisciplinary seminars, formal and informal conversations and research collaboration between the natural and social sciences are all examples of small contributions in this respect. In this way, reflexive capacity and vocabulary may be built: ELSA-researchers learn more about the daily practices and vision of nanoresearch, and nanoresearchers learn more about the theories and resources that exists for ethical and social appraisal of science and technology.

Despite these practical challenges, this second notion of responsible nanoresearch would entail that if one managed to institutionalise deliberation between sectors and levels, nanoresearch as a profession would be responsible. As Pellizzioni [17] describes, the conviction that scientific certainty is unattainable (either ontologically or epistemologically) makes the idea of responsibility as the ability to justify choices rationally in retrospect, fall apart. The acknowledgement of scientific uncertainty favours a notion of responsibility that resembles that of responsiveness. Nanoresearchers are responsible if they are willing to enter into dialogue with and be confronted by the beliefs and concerns of other actors, individuals and stakeholders in the development of nanoresearch, and rethink their work in accordance with such queries. In this line of arguing, responsible nanoresearch is taking seriously other actors as conversational partners and co-producers of the nanofuture, funded on an understanding that nanoresearch is one among many relevant fields of knowledge, and the scientific one among many possible framings of the development of nanoST.

Responsible Nanoresearch as Increased Awareness of Moral Choices

Institutionalisation of deliberation and communication between levels and sectors in nanoresearch may have a significant potential to prevent instances of environmental, social, ethical and health-related harm 
from nanoST by revealing science/society entanglement and scientific uncertainties. It may steer nanoST in a more socially desirable and robust direction by broad inclusion and negotiation of values in scientific decisions. Even when scientific uncertainties and plurality of values get exposed by deliberation and communication, however, they pose fundamental challenges for (personal and political) decision-making. The awareness of this can be paralysing in closing down decision processes, as it renders the fundamental decision tool of rational weighing of benefits against risks ineffective. The third notion of responsible nanoresearch starts from the acknowledgement of how this shortcoming ultimately leads to personal moral judgement and choice.

In the conversations, two of the types came across as unsettled and in a process of making sense of their own personal roles within nanoresearch. The uncertainty-minded nanoresearcher pointed to the inability to understand the responses in risk-research for nanoparticles, and had come to consider the possibility that risk-research might be unable, temporarily or permanently, to predict the behaviour and reactions of nanoparticles even under the extremely simplified conditions of the laboratory. Talking about this made the uncertainty-minded nanoresearcher uneasy and seemed to challenge her sense of whether being involved in nanoparticle risk-research, at the end of the day, made her feel responsible. Likewise, for ironic nanoresearchers, the confrontation with the EC-CoC made the label of nanoresearcher feel uncomfortable, and led to reflections about the personal association and involvement with the enterprise of nanoST. Deliberation or conversation can lead to confrontation with own values, which then has to be thought through and made sense of at a personal level. The third notion of responsibility involves cultivating one's sensitivity for recognising when personal moral judgements and choices are being made in the midst of professional life. This sensitivity may be generated through deliberation, but is not identical with it. Likewise, in contrast to deliberation such sensitivity does not necessarily aim to assist political decision-making directly, but is a resource for personal day to day decision-making. Not being instrumental, it is rather a notion of responsibility as a way of being.

One way to approach this notion of responsibility may be along the lines of Hannah Arendt [2]. She emphasises the need for each individual to think in order to make moral judgements, and act responsible. 'Thinking', is used by Arendt here in the particular meaning of inner dialogue, and her argument is that individuals who regularly rehearse the practise of thinking, in this sense, will find it increasingly unbearable to act against their own convictions and values. It involves questioning one's own actions, in light of own values. Thinking entails being alone with oneself, providing a strong motivation for being able to like oneself. It hence strengthens the ability and motivation for making moral judgements, as well as the mindfulness to when moral judgements are being made. "The manifestation of the wind of thought is no knowledge; it is the ability to tell right from wrong, beautiful from ugly. And this indeed may prevent catastrophes, at least for myself, in the rare moments when the chips are down." ([2], p 189). Although the catastrophe Arendt had in mind was a quite different one from those one may envision resulting from nanoST, her emphasis on the individual inner dialogue as a requirement for responsibility remains convincing. As scientific uncertainty may paralyse the rational balancing of benefits and risks, her point is precisely that in lack of knowledge, or even in lack of the skill or resources to pursue knowledge, to remain thinking ensures the individual's personal ability to feel responsible. And the individual sense of feeling able to perform its professional tasks responsibly is crucial. Responsible nanoresearch in this respect may be not to put away pertinent concerns raised in own contemplation, in dialogue with peers or by other stakeholders, even if not able to solve them, but to remain committed to thinking through these kinds of questions on a regular basis. In Arendt's analysis, however, thinking is (and should be) connected to praxis, to action and the interaction with fellow citizens. In this sense it does not replace the notions of responsibility discussed above, but contributes with another element to what it takes for the individual nanoresearcher to feel responsible, even when she takes into account that what she does is part of a larger reality. This adds value to the deliberative efforts described above.

In terms of Pellizzioni's [17] analytic disentanglement of responsibility, this may mean to add a kind of responsibility driven by 'before-the-event' motifs and 'in-order-to' factors, the kind of responsibility he calls care. It incorporates the sense of responsibility taken $e x$ ante, motivated from within (the professional role of 
nanoresearch). In contrast to responsiveness, this kind of responsibility is not the reaction to questions or accusations from outside, but requires an active (rather than defensive) understanding of the role as nanoresearcher also in terms of the application and implications of research and research activities. In addition to the responsibilities assigned to the role of nanoresearch by the proposition posed in "Responsible Nanoresearch as Deliberation Across Levels and Sectors" it suggests the necessity of an internally initiated and personal thinking that goes beyond action.

Thinking in this sense is not something that requires specialised cognitive skills, Arendt argues; all it requires is devotion and occasion, because "...the inability to think is [...] the ever-present possibility for everyonescientists, scholars, and other specialists in mental enterprises not excluded." ([2], p. 187). Even if the possibility not to think may be tempting, there are many individuals, researchers and others, who enter into the inner dialogue because it is what makes them feel responsible. Fjelland [8] interprets the story about David Parnas, the researcher who withdrew from the US 'Star Wars' initiative in 1985 and publicly criticised the project [16], as such an example. Fjelland distils Parnas' sense of professional responsibility as 1) not to rely on any external authority to make decision for him, 2) not to ignore ethical and moral issues, and 3) to make sure that he solves the real problem, not simply providing short term satisfaction to his supervisors.

The responsibility to remain thinking in this sense may sound like a heavy burden to place upon the individual nanoresearchers, but if the institutionalisation of deliberation and engagement in the previous section represented a paradox, an institutionalised requirement for contemplation may seem absurd. Still, although thinking as such may not be installed by directives, it may be encouraged and supported by the institutions of research. Likewise, spaces and occasions for contemplation may be created and sheltered. This is what good governance should be about, although it remains beyond the scope of this paper to attempt to answer how to cultivate mindfulness, increased moral sensitivity, and thinking. We believe however that practises like the inclusion of ethics, philosophy and ELSA-elements in research education, as well as the generation of 'mixed cultures' through broad and interdisciplinary research programmes may provide some of the answer. Indeed, governance as something that in effect slows down productivity. It may lead to less favourable conditions for excellent nanoresearchers and more opportunities for social-democratic nanoresearchers, ironic nanoresearchers and uncertainty-minded nanoresearchers.

At the end of the day, the decision to encourage the nanoresearchers' occasion and motivation to act responsible in this third way is connected to how qualities like mindfulness is valued by the institutions of research compared to for instance those of efficiency and productivity. There is no way around an evaluation of the adequacy and desirability of contemporary science and innovation policies. Most governments in the early 21 st century see efficiency and productivity and the fast development of science and technology as a crucial element in the need to maintain innovation and economic growth. There may still be a place for inefficient mindfulness within this kind of regime, if one also believes that there may be significant risks and hazards in the course of S\&T development. For many critics of the innovation and growth policies, however, these policies appear as a result of a tragic institutional lock-in that leads to a continued escalation of unsustainable modes of civilization. Excluding the path of political revolutions, one may ask what possibilities there are of change other than that which will force itself through by severe ecological crisis. Seen from this perspective, mindfulness and care is no recipe for successful change. Rather, it is a moral imperative: It appears reckless if powerful actors such as scientists are encouraged not to doubt their actions or the institutional arrangements in which they operate in what amounts to a monolithic ideology of innovation and growth.

Open Access This article is distributed under the terms of the Creative Commons Attribution Noncommercial License which permits any noncommercial use, distribution, and reproduction in any medium, provided the original author(s) and source are credited.

\section{References}

1. Arendt H (1958) The human condition, 2nd edn. The University of Chicago Press, Chicago

2. Arendt H (1971) Thinking and moral considerations. In: Kohn J (ed) (2003) Responsibility and judgement (pp. 159189). New York: Schocken Books 
3. Craye M (2009) Governance of nanotechnologies: learning from past experiences with risks and innovative technologies. In: The final report of the project 'Coordination Action on Building Robust, Integrative inter-Disciplinary Governance models for Emerging and Existing risks' (Risk Bridge) (pp. 108-150). European Commission

4. Davies S, Macnaghten P, Kearnes M (eds) (2009) Reconfiguring responsibility: lessons for public policy. In the report on Deepening Debate on Nanotechnology, Durham: Durham University

5. European Commission (EC) (2001) White paper on European governance, COM(2001) 428

6. European Commission (EC) (2008) Recommendation on a code of conduct for responsible nanoscience and nanotechnology research, C(2008) 424. European Commission, Brussels

7. Ferrari A, Nordmann A (eds) (2009) Reconfiguring responsibility: lessons for nanoethics. In the report on Deepening Debate on Nanotechnology, Durham: Durham University

8. Fjelland R (1999) Vitenskap mellom sikkerhet og usikkerhet. Ad Notam Gyldendal, Oslo

9. Gibbons M (1999) Science's new social contract with society. Nature 402, December supplement

10. Jonas H (1984) The imperative of responsibility - in search of an ethics for the technological age. The University of Chicago Press, Chicago
11. Jones R (2009) Are you a responsible nanoscientist? Nat Nanotechnol 4:336

12. Kjølberg K, Wickson F (2007) Social and ethical interactions with nano: mapping the early literature. Nanoethics 1:89-104

13. Næss A (1976) Økologi, samfunn og livsstil. Universitetsforlaget, Oslo

14. Nordmann A (2009) European experiments. Osiris 24:278-302

15. Nowotny H, Scott P, Gibbons M (2001) Re-thinking science: knowledge and the public in an age of uncertainty. Polity, Cambridge

16. Parnas DL (1985) Software aspects of strategic defense systems. Commun ACM 28:1326-1335

17. Pellizzioni L (2004) Responsibility and environmental governance. Environ Polit 13:541-565

18. Polanyi M (1946) Science, faith and society. The University of Chicago Press, Chicago

19. Tallacchini M (2009) Governing by values, EU ethics: soft tool, hard effects. Minerva 47:281-306

20. von Schomberg R (2007) From the ethics of technology towards an ethics of knowledge policy \& knowledge assessment. Working document, Brussels: European Commission, Directorate-General Research

21. von Schomberg R (2010) Introduction. In: von Schomberg $\mathrm{R}$, Davies $\mathrm{S}$ (eds) Understanding public debate on nanotechnologies options for framing public policy. A report from the European Commission Services 